\title{
NifL of Klebsiella pneumoniae: redox characterization in relation to the nitrogen source
}

\author{
Kai Klopprogge, Ruth A. Schmitz * \\ Institut für Mikrobiologie und Genetik, Universität Göttingen, Grisebachstr. 8, 37077 Göttingen, Germany
}

Received 6 December 1998; received in revised form 4 March 1999; accepted 19 March 1999

\begin{abstract}
In Klebsiella pneumoniae, NifL modulates the activity of the transcriptional activator NifA in response to combined nitrogen or external molecular oxygen. We recently showed that $K$. pneumoniae NifL is a flavoprotein which apparently senses oxygen through a redox-sensitive, conformational change. In order to study whether the nitrogen signal might be transmitted to NifA through a stable modification of NifL we characterized the redox properties of NifL synthesized in Escherichia coli in the presence of different nitrogen sources. FAD analyses showed that purified NifL carried FAD as cofactor independent of nitrogen and oxygen availability. The redox potential of NifL synthesized in the presence of ammonium was $-277 \pm 5 \mathrm{mV}$ at $\mathrm{pH} 8.0$ and $25^{\circ} \mathrm{C}$, as determined by reduction with dithionite or with enzymatic reduction by xanthine oxidase in the presence of methyl viologen as redox mediator. When synthesized under nitrogen-limiting conditions, NifL showed a redox potential of $-274 \pm 6 \mathrm{mV}$ at $\mathrm{pH} 8.0$ and $25^{\circ} \mathrm{C}$. Fully reduced NifL fractions, synthesized under either condition listed above, reoxidized rapidly in the presence of molecular oxygen. These results indicate that for NifL synthesized in E. coli, the redox potential of the NifL-bound FAD is not influenced by the nitrogen source. The two NifL fractions differed, however, in that a non-flavin specific absorbance at $420 \mathrm{~nm}$ was found only in NifL synthesized in the presence of ammonium. (C) 1999 Published by Elsevier Science B.V. All rights reserved.
\end{abstract}

Keywords: Klebsiella pneumoniae; Regulation of nitrogen fixation; NifL; Flavoprotein; Redox potential

\section{Introduction}

In the free-living diazotroph Klebsiella pneumoniae expression of nitrogen fixation (nif) genes is regulated by the products of the nifLA operon ([1,2] and publications cited therein). NifA activates transcription of all nif genes (except nifLA) by an alternative holoenzyme form of RNA polymerase, $\sigma^{54}$-holoenzyme. NifL, which is the negative regulator of the nif genes, inhibits the transcriptional activation by NifA in re-

\footnotetext{
* Corresponding author. Fax: +49 (551) 393793; E-mail: rschmit@gwdg.de
}

sponse to combined nitrogen or external molecular oxygen. NifL is composed of an N-terminal and a Cterminal domain. Its inhibitory function appears to lie in the $\mathrm{C}$-terminal domain, and the $\mathrm{N}$-terminal domain is thought to mediate the response to environmental changes in the status of oxygen and combined nitrogen $[3,4]$.

We have recently shown that $K$. pneumoniae NifL is a flavoprotein, which contains an N-terminally bound FAD as cofactor [5]. We therefore hypothesized that under nitrogen and oxygen-limiting conditions, the inhibitory form of NifL is transformed to the non-inhibitory form upon reduction of the $\mathrm{N}$ terminally bound FAD. NifL apoprotein completely 
lacking the cofactor is still able to inhibit NifA activity in vitro [5], showing that the FAD cofactor is not directly required for the inhibitory function of NifL. However, this leaves open the possibility that FAD mediates the conversion of NifL to the noninhibitory form upon reduction of this N-terminal bound moiety. In Azotobacter vinelandii NifA activity is also modulated by an FAD-containing NifL regulatory protein acting as a redox switch in response to the environmental oxygen status [6]. Hill et al. [6] and Machereaux et al. [7] showed that the in vitro reduction of the flavin moiety of NifL by sodium dithionite [6] or by the flavoheme protein HMP from Escherichia coli with NADH [7] resulted in a non-inhibitory form of NifL.

The mechanism by which nitrogen is sensed in $K$. pneumoniae and $A$. vinelandii is currently not understood. It was shown that $K$. pneumoniae NifL [8] and A. vinelandii NifL [9] both modulate NifA activity in $E$. coli in response to the level of combined nitrogen, suggesting that NifL might respond to a generalized or globally sensing nitrogen signal transduction pathway. In $K$. pneumoniae, Holtel and Merrick [10] showed that PII $(g \ln B$ gene product) is not required for signaling the nitrogen status. Recently, $\mathrm{He}$ et al. [11] provided evidence that the second PII protein, GlnK, might be involved in signaling the nitrogen status. One possible mechanism for the nitrogen sensing pathway in K. pneumoniae - hypothesizing NifL as transducer for the nitrogen signal to NifA - is that in the presence of combined nitrogen the redox potential of NifL-bound FAD is lowered by a covalent post-translational modification such that it can no longer be reduced by its physiological electron donor. To test whether the redox properties of NifL change with the nitrogen status of cells we determined the redox potential of NifL synthesized in E. coli under nitrogen-limiting conditions and in the presence of ammonium, a preferred nitrogen source.

\section{Materials and methods}

\subsection{Plasmids}

pJES794 encoding MBP-NifL under the control of the tac promoter is described by Narberhaus et al.
[3]. pJES283 encoding NifL under the control of the $\mathrm{T} 7$ promoter is described by Lee et al. [12].

\subsection{Cell extracts and purification of maltose binding protein (MBP)-NifL}

MBP-NifL was synthesized in NMC1529 [8] carrying pJES794. Expression of fusion protein was induced from the tac promoter with $50 \mu \mathrm{M}$ isopropyl- $\beta$-D-thiogalactopyranoside (IPTG) when cultures reached an $\mathrm{OD}_{600}=0.6$. The cultures were grown at $30^{\circ} \mathrm{C}$, aerobically or anaerobically under $\mathrm{N}_{2}$ gas, and in modified $\mathrm{K}$ medium containing $4 \mathrm{mM}$ glutamine or $10 \mathrm{mM}$ ammonium as the sole nitrogen source $[5,8]$. After disruption of cells in breakage (B) buffer [13] and centrifugation at $20000 \times g$, fusion proteins were purified from the supernatant by amylose affinity chromatography. Anaerobic purifications were performed in the presence of $2.0 \mathrm{mM}$ dithiothreitol and under a nitrogen atmosphere in an anaerobic chamber.

\subsection{FAD analyses}

Purified MBP-NifL (0.2-2 mg) was heat denatured and extracted with $5 \%(\mathrm{w} / \mathrm{v})$ trichloroacetic acid. The extracted compounds were analyzed by reversedphase HPLC at room temperature as described by Schmitz [5].

\subsection{Determination of the redox potential of NifL-bound FAD}

Purified MBP-NifL fractions were concentrated to 20-50 $\mu \mathrm{M}$ using polyethylene glycol. The redox potentials of these MBP-NifL fractions in B buffer $(\mathrm{pH}$ 8.0) were determined according to Massey [14] by reducing the flavoprotein in either of two ways: either with dithionite or with the electron-generating reaction with xanthine oxidase/xanthine. $200 \mu \mathrm{l}$ of a 20-50 $\mu \mathrm{M}$ MBP-NifL solution was incubated anaerobically in a cuvette at $\mathrm{pH} 8.0$ and $25^{\circ} \mathrm{C}$ with $2 \mu \mathrm{M}$ methyl viologen as redox mediator and a redox indicator ( $2 \mu \mathrm{M}$ phenosaphranine). Anaerobiosis was achieved by flushing the sealed cuvette with molecular nitrogen several times. Dithionite reduction was started by adding dithionite stepwise to final concentrations of 10, 20 and $60 \mu \mathrm{M}$. Spectral changes for 
each reduction step were recorded (Kontron Uvikon 930). When using the electron-generating reaction with xanthine oxidase, $200 \mu \mathrm{M}$ xanthine was included in the cuvette and the reduction started by adding xanthine oxidase to a final concentration of approx. $20 \mathrm{mU} / \mathrm{ml}$. The redox potential was determined by plotting the data as described by Minneart [15]: for each time point the concentration of oxidized and reduced MBP-NifL was calculated from the spectra and $\log \left(\mathrm{FAD}_{\mathrm{ox}} / \mathrm{FAD}_{\text {red }}\right)$ was plotted versus $\log$ ( phenosaphranine $_{\mathrm{ox}} /$ phenosaphranine $\left._{\mathrm{red}}\right)$.

In a separate method, the redox potential of MBPNifL was also determined by reducing the protein with dithionite and measuring the redox potential with an electrode (Ingold Pt 4805-M8/120). For this method, a $3 \mathrm{ml}$ sample of enzyme was incubated in an anaerobic cuvette in the presence of $5 \mu \mathrm{M}$ methyl viologen and titrated in an anaerobic chamber by adding aliquots of $5 \mu \mathrm{M}$ dithionite. After addition of dithionite, the mixture was incubated at room temperature until the redox electrode showed no further change. The redox potentials of MBP-NifL samples were calculated using the Nernst equation.

\subsection{Purification of NifL apoprotein from inclusion bodies by denaturation with urea}

NifL was synthesized in E. coli BL21 carrying pJES283 as described by Lee et al. [12]. Expression of the protein was induced from the $\mathrm{T} 7$ promoter with $50 \mu \mathrm{M}$ IPTG when cultures reached an $\mathrm{OD}_{600}=0.6$. The cultures were grown aerobically at $30^{\circ} \mathrm{C}$ in maximal induction medium [13] or in minimal medium with glutamine as limiting nitrogen source. After disruption of cells in breakage buffer and centrifugation at $20000 \times g$ NifL was purified from inclusion bodies under aerobic conditions by denaturation with $8 \mathrm{M}$ urea and refolding by dialysis into breakage buffer overnight at $4^{\circ} \mathrm{C}$ as described by Lee et al. [12].

\subsection{Determination of non-heme iron and protein}

Non-heme iron was determined colorimetrically as described by Fish [16]. Protein was determined via the method of Bradford [17] with the Bio-Rad protein assay using bovine serum albumin as standard.

\subsection{SDS-PAGE analyses and heme peroxidase activity stain}

Sodium dodecyl sulfate-polyacrylamide gel electrophoresis was performed according to Laemmli using $12.8 \%$ acrylamide [18]. Gels were stained either for protein with Coomassie brilliant blue or with 3,3' $, 5,5^{\prime}$-tetramethyl benzidine (TMBZ, $2 \mathrm{mM}$ ) and $30 \mathrm{mM} \mathrm{H} \mathrm{H}_{2} \mathrm{O}_{2}$ to reveal heme peroxidase activity as described by Thomas et al. [19]. Protein samples were not denatured by heating or treated with $\beta$-mercaptoethanol when heme peroxidase activity was analyzed.

\section{Results}

We chose to examine the possible influence of the nitrogen availability in cultures on the redox properties of $K$. pneumoniae NifL. For this study, NifL was synthesized and purified from $E$. coli grown in minimal medium with ammonium or with a limiting nitrogen source. In order to keep NifL in solution a protein fusion with the maltose binding protein (MBP) was used [12]. Synthesis of MBP-NifL was induced to a level at which NifL function is regulated normally in response to oxygen and combined nitrogen in $K$. pneumoniae and in a heterologous $E$. coli system $[13,8]$.

\subsection{FAD analyses of K. pneumoniae NifL synthesized in $E$. coli under various conditions}

To test whether NifL from $K$. pneumoniae carries FAD as cofactor independent of the nitrogen source, MBP-NifL was expressed in $E$. coli grown under various conditions, purified to approx. 97\% homogeneity (data not shown) and analyzed for cofactors. MBP-NifL purified from all culturing conditions examined - aerobically or anaerobically and with a limiting nitrogen source (glutamine) or ammonium - contained FAD as cofactor. The proportions of FAD detected in proteins varied between $0.25 \mathrm{~mol}$ and 0.45 mol FAD per mol MBP-NifL, which is due to different losses of cofactor during purification procedures. These results indicate that $K$. pneumoniae NifL carries FAD as cofactor independent of the 


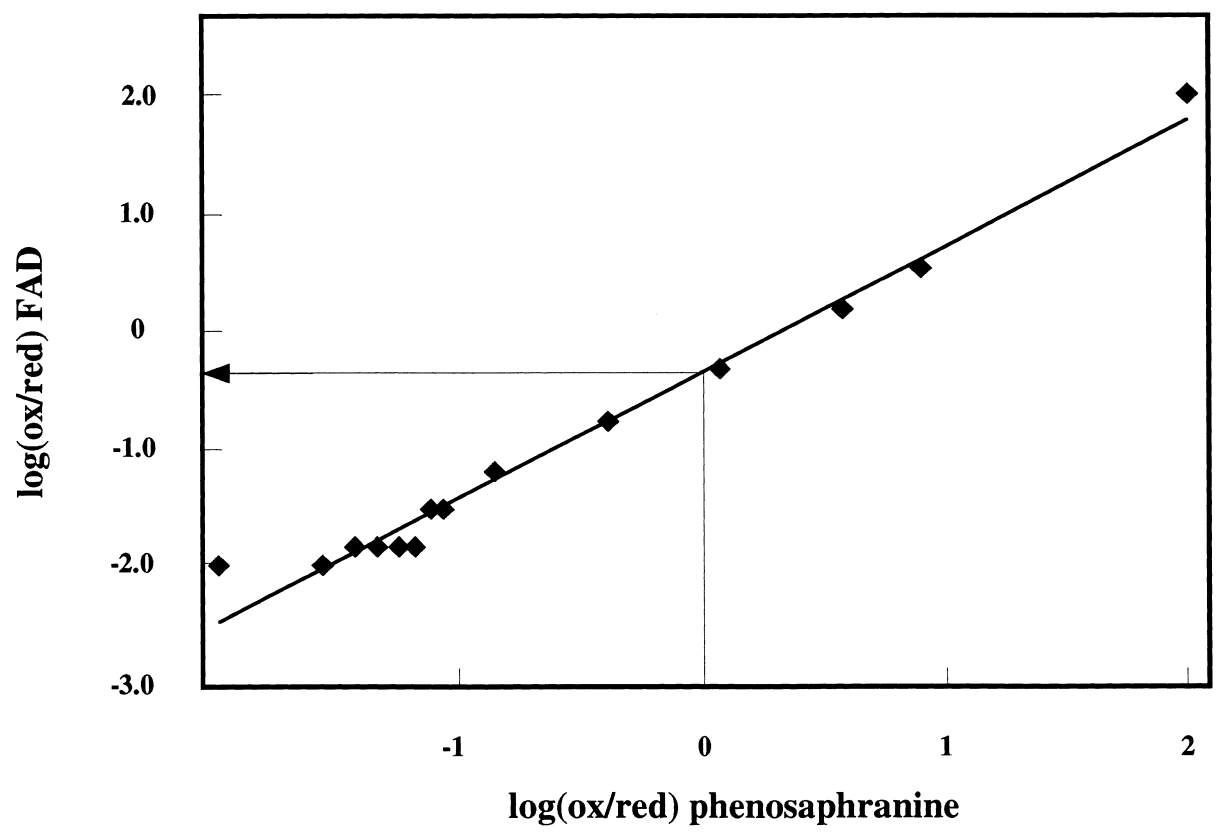

Fig. 1. Nernst plot of the reduction of MBP-NifL with dithionite. $20 \mu \mathrm{M}$ MBP-NifL in B buffer pH 8.0 synthesized aerobically in minimal medium in the presence of ammonium was stepwise reduced at $25^{\circ} \mathrm{C}$ with dithionite to a final concentration of $60 \mu \mathrm{M}$ in the presence of $2 \mu \mathrm{M}$ methyl viologen and $20 \mu \mathrm{M}$ phenosaphranine as redox indicator $\left(E_{0}=-282 \mathrm{mV}\right.$ at $\mathrm{pH} 8$ assuming that the $\mathrm{pH}$ de-

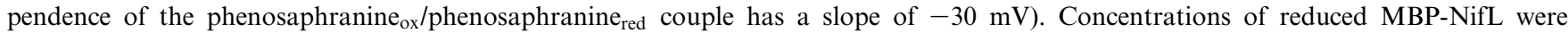
calculated for each reducing step from the respective absorbance at $450 \mathrm{~nm}$ and $\log \left(\mathrm{FAD}_{\mathrm{ox}} / \mathrm{FAD}_{\text {red }}\right)$ plotted versus $\log \left(\right.$ phenosaphranine $_{\mathrm{ox}} /$ phenosaphranine $\left._{\text {red }}\right)$ according to Minneart [15].

availability of nitrogen and oxygen in the culture medium.

\subsection{Determination of redox potentials}

In order to study whether the nitrogen availability in cultures is affecting the redox properties of NifLbound FAD, we determined the redox potentials of MBP-NifL, synthesized in minimal medium with ammonium or with glutamine as limiting nitrogen source. MBP-NifL preparations for the following redox titrations were in general synthesized under aerobic growth conditions followed by cell breakage and purification in the presence of oxygen. Reducing flavoproteins in the presence of a redox-sensitive dye provides a convenient method to determine the redox potential of protein-bound FAD cofactors. This method is based on the equilibration of reducing equivalents between the flavin moiety of the flavoprotein and a dye of a known redox potential [14]. We used two methods to reduce MBP-NifL in the presence of $2 \mu \mathrm{M}$ phenosaphranine as redox indicator $\left(E_{0}{ }^{\prime}=-252 \mathrm{mV}\right.$ at $\left.\mathrm{pH} 7.0\right)$ : chemically, by add- ing dithionite to the solutions, or enzymatically, by incubating MBP-NifL with xanthine/xanthine oxidase. For reduction by dithionite, $20-50 \mu \mathrm{M}$ of purified MBP-NifL in B buffer ( $\mathrm{pH}$ 8.0) was treated with stepwise additions of dithionite (final concentrations of $10,20,40$ and $60 \mu \mathrm{M})$. Spectra were recorded after each step of addition. The flavin-specific absorbance at $450 \mathrm{~nm}$ revealed that the NifL-bound FAD was completely reduced after adding $60 \mu \mathrm{M}$ dithionite; further addition of dithionite did not result in any further absorbance decline at $450 \mathrm{~nm}$. In samples that were enzymatically reduced, the reducing reaction was started by adding a catalytic amount of xanthine oxidase. The spectra of these samples were recorded every $15 \mathrm{~min}$ thereafter. To calculate the redox potential of MBP-NifL, the concentration of oxidized and reduced MBP-NifL was calculated for each time point from their respective absorbances at $450 \mathrm{~nm}$ and the $\log \left(\mathrm{FAD}_{\mathrm{ox}} / \mathrm{FAD}_{\mathrm{red}}\right)$ plotted versus $\log$ (phenosaphranine ox $_{\text {p }}$ phenosaphranine $_{\text {red }}$ ) which was determined from the dye absorbance at $525 \mathrm{~nm}$ (Fig. 1, showing the Nernst plot of NifL synthesized aerobically in minimal medium 

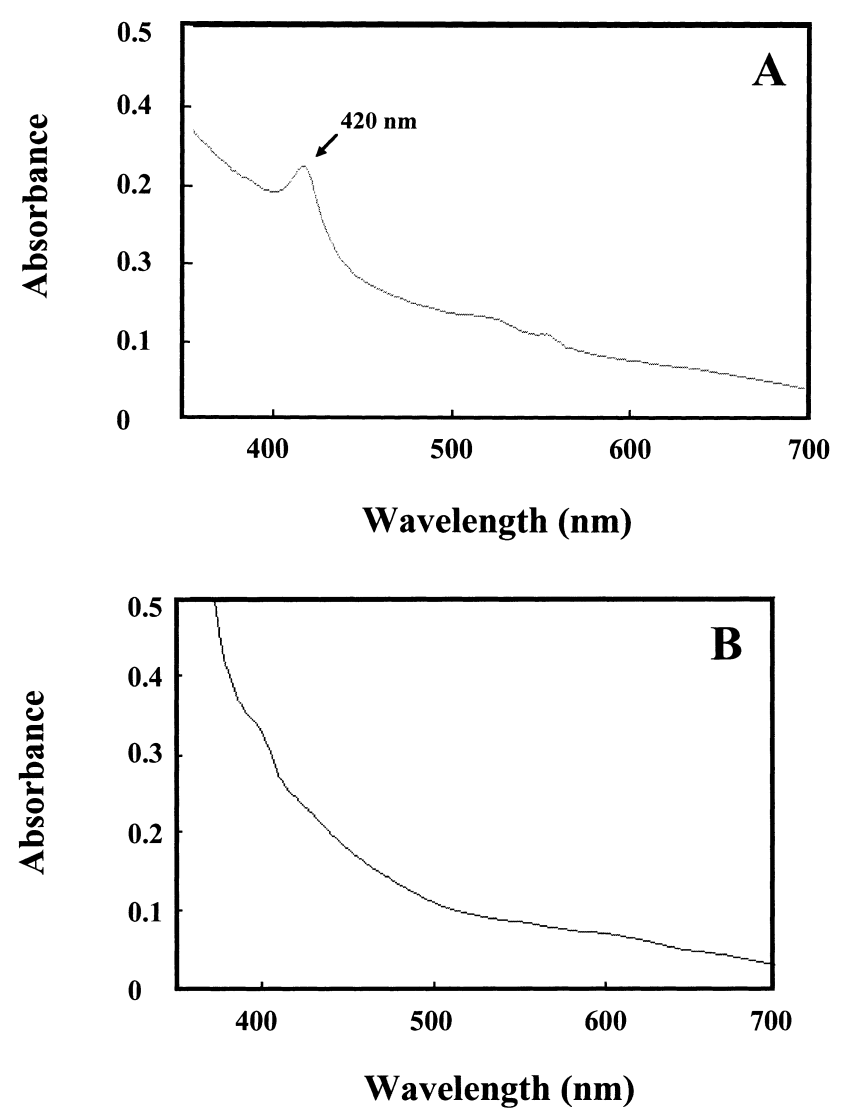

Fig. 2. Absorbance analyses after reduction of MBP-NifL with sodium dithionite. $20 \mu \mathrm{M}$ purified MBP-NifL in B buffer $(\mathrm{pH}$ 8.0) was reduced at $25^{\circ} \mathrm{C}$ with dithionite to a final concentration of $60 \mu \mathrm{M}$ in the presence of $2 \mu \mathrm{M}$ methyl viologen. MBPNifL was synthesized in the presence of $10 \mathrm{mM}$ ammonium (A) or $4 \mathrm{mM}$ glutamine (B).

in the presence of ammonium). The redox potential was calculated according to Minneart [15] from the $\mathrm{y}$-axis intercept where $\log$ (phenosaphranine ox $_{\text {pheno- }}$ saphranine $\left._{\text {red }}\right)$ equals zero: $E_{0}(\mathrm{NifL})=-282 \mathrm{mV}-$ $(-0.34 \times 30 \mathrm{mV})=-272 \mathrm{mV}\left(E_{0}(\right.$ phenosaphranine $)$ at $\mathrm{pH} 8=-282 \mathrm{mV}$, assuming that the $\mathrm{pH}$ dependence of the phenosaphranine $($ ox/red $)$ couple has a slope of $-30 \mathrm{mV}$ ). From ten independent MBPNifL preparations synthesized aerobically in the presence of ammonium, the redox potential was determined to be $-277 \pm 5 \mathrm{mV}$. The redox potential of MBP-NifL synthesized in the presence of oxygen under nitrogen-limiting conditions was $-274 \pm 6$ $\mathrm{mV}$ (data from four independent preparations). In the presence of molecular oxygen reoxidation of MBP-NifL which was fully reduced during the proc- ess of redox titration occurred rapidly, regardless of whether it was synthesized under nitrogen limitation or in the presence of ammonium. The finding that the redox potentials do not differ between MBP-NifL preparations isolated from cells grown aerobically under conditions of nitrogen limitation or in the presence of ammonium suggests that the nitrogen source has no direct influence on the redox characteristics of NifL when synthesized in E. coli.
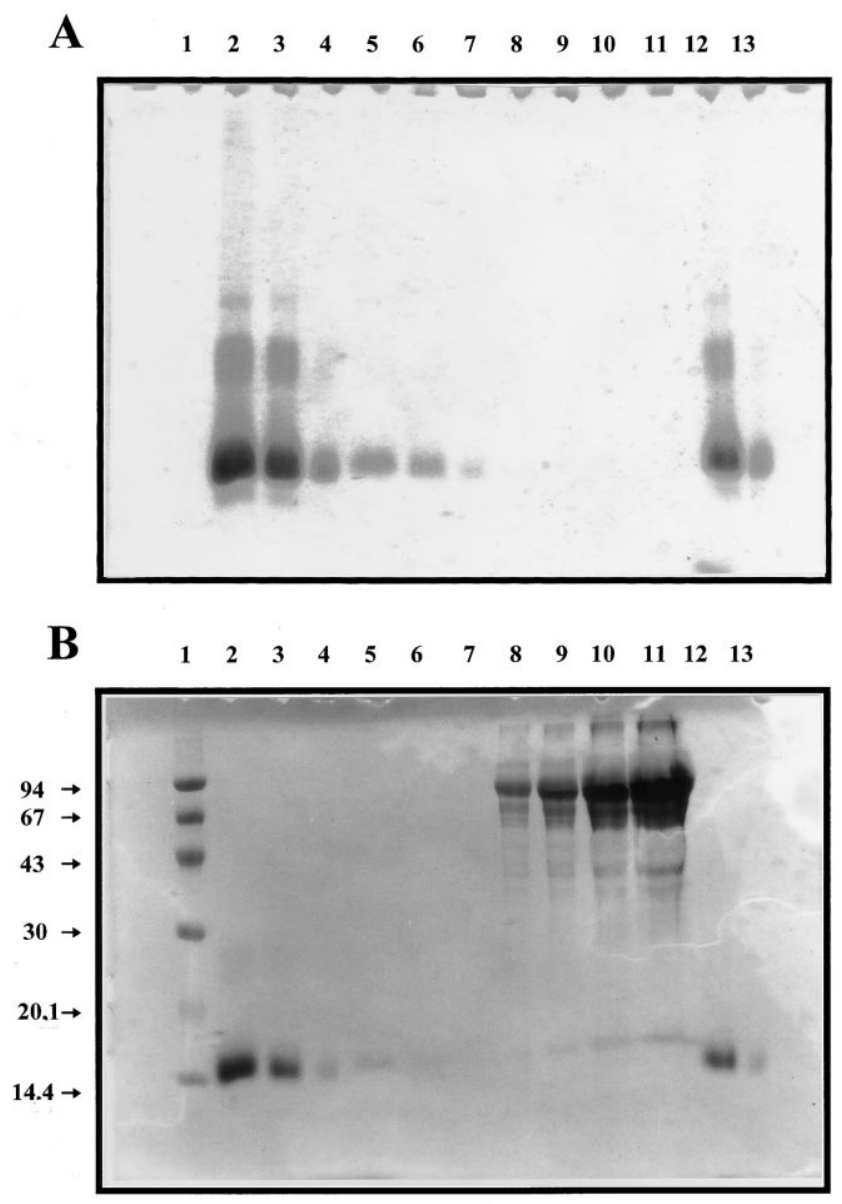

Fig. 3. Analyses of purified MBP-NifL for peroxidase activity with TMBZ and $\mathrm{H}_{2} \mathrm{O}_{2}$ (heme stain). MBP-NifL synthesized in the presence of ammonium was analyzed by SDS gel electrophoresis (12.8\% acrylamide) and stained with 3,3',5,5'-tetramethyl benzidine (TMBZ, $2 \mathrm{mM}$ ) and $30 \mathrm{mM} \mathrm{H} \mathrm{H}_{2} \mathrm{O}_{2}$ to reveal the heme peroxidase activity (A) and subsequently with Coomassie brilliant blue for protein (B). Lane 1 contained $5 \mu \mathrm{g}$ protein molecular mass standard (Pharmacia); lanes 2-7 cytochrome $c$ from horse heart (Fluka), 300, 150, 30, 30, 15, and 3 pmol, respectively; lanes 8-11 concentrated purified MBPNifL fractions, 75, 150, 300 and 600 pmol, respectively and lanes 12 and 13,150 and 30 pmol cytochrome $c$. 

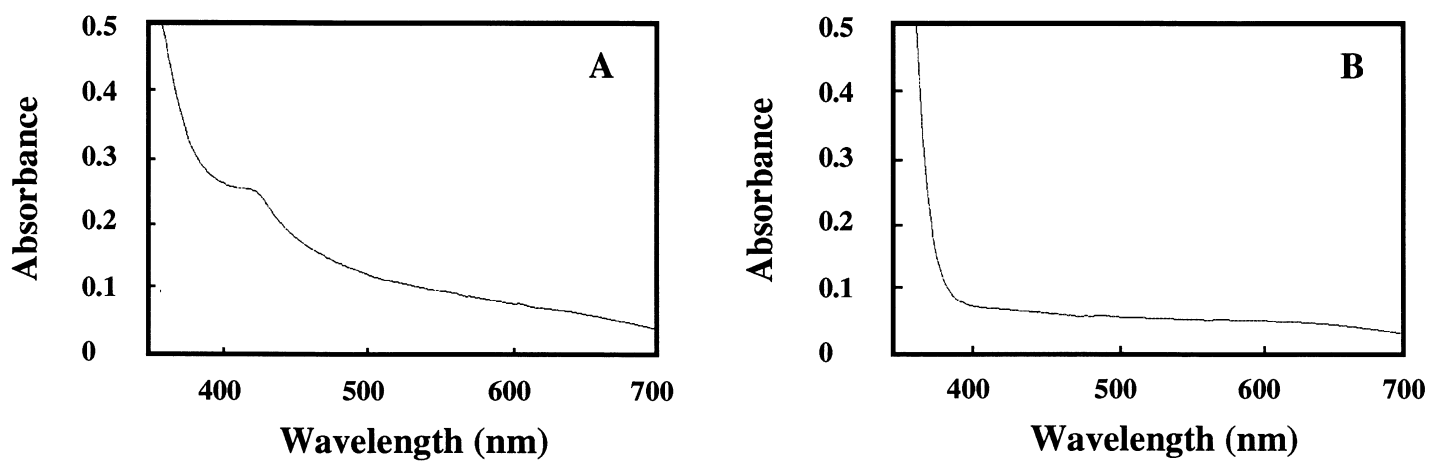

Fig. 4. Absorbance spectrum of fully reduced NifL apoprotein. The spectra of NifL apoproteins in B buffer ( $\mathrm{pH} 8.0$ ) were recorded at room temperature after reducing the protein fractions with sodium dithionite (final concentrations $75 \mu \mathrm{M}$ ). Apo-NifL (57 $\mu \mathrm{M}$ and $15 \mu \mathrm{M}$, respectively) was purified from cells grown under nitrogen excess in maximal induction medium (A) or in minimal medium with glutamine as limiting nitrogen source (B).

The redox potentials were also determined by a second method. In this method, the flavin moiety of purified MBP-NifL was titrated with dithionite and the solution potential measured with a redox electrode after equilibration with each addition. The redox state of the flavin was followed spectroscopically. This method for determining the redox potentials of MBP-NifL preparations gave the same results as the dye-linked assays described above (data not shown).

\subsection{Analyses of iron and heme peroxidase activity of purified MBP-NifL}

In purified MBP-NifL fractions synthesized in the presence of ammonium an interesting absorbance centered around $420 \mathrm{~nm}$ was found, which partially overlaid the absorbance from the flavin at $450 \mathrm{~nm}$ and persisted during reduction processes (Fig. 2A). Careful reviewing the MBP-NifL difference spectrum we published recently ([5], Fig. 1) revealed that MBPNifL synthesized in $E$. coli under nitrogen excess in maximal induction medium also showed the presence of the $420 \mathrm{~nm}$ absorbance peak. Purified MBP-NifL synthesized under nitrogen limitation with glutamine as nitrogen source, however, did not show this absorbance at $420 \mathrm{~nm}$ (Fig. 2B). To rule out that the absorbance around $420 \mathrm{~nm}$ of MBP-NifL fractions synthesized in the presence of ammonium arises from an iron-containing cofactor of NifL, we measured the iron concentration of the purified protein. Using the method described by Fish [16], no significant amounts of iron were found (less than $0.2 \mathrm{~mol}$ per mol which is in the same range as was found for purified MBP).

In order to analyze whether the absorbance at 420 $\mathrm{nm}$ is based on a contamination by a heme containing protein we determined the peroxidase activity of purified MBP-NifL fractions with TMBZ- $\mathrm{H}_{2} \mathrm{O}_{2}$. Purified MBP-NifL fractions synthesized in the presence of ammonium (75-600 pmol) were analyzed by gel electrophoresis and subsequently stained for peroxidase activity with TMBZ- $\mathrm{H}_{2} \mathrm{O}_{2}$ (Fig. 3A), followed by staining for proteins using Coomassie brilliant blue (Fig. 3B). As a control cytochrome $c$ was analyzed in a range of 3-300 pmol. In contrast to no peroxidase activity in case of the purified MBP-NifL fractions (maximal $600 \mathrm{pmol}$ ), peroxidase activity of cytochrome $c$ was still detectable at 3 pmol. This indicates that a possible heme contamination of the MBP-NifL fractions would be significantly lower than $0.5 \%$.

\subsection{Spectral properties of NifL purified from inclusion bodies by denaturation with urea}

The $420 \mathrm{~nm}$ absorbance feature, which is only found when MBP-NifL is synthesized in the presence of ammonium, might originate from a covalent modification of the protein moiety in the presence of ammonium. To test this possibility we purified NifL apoprotein (apo-NifL) to homogeneity from inclusion bodies synthesized in $E$. coli under aerobic conditions and nitrogen excess (maximal induction medium) by denaturation with $8 \mathrm{M}$ urea and subsequent renaturation in the presence of oxygen as de- 
scribed in Section 2 [12]. Spectrofluorometric analyses of trichloroacetic acid extracts from renatured NifL preparations revealed that the renatured NifL completely lacks its FAD cofactor. However, this apoprotein fraction of NifL still retains an absorption at $420 \mathrm{~nm}$ which cannot be reduced by the addition of dithionite (Fig. 4A). The absorbance at 420 $\mathrm{nm}$ is detectable and significantly higher than the slope in absorbance between 400 and $500 \mathrm{~nm}$ which is also present in the MBP-NifL preparations carrying the cofactor (Fig. 2). These findings indicate that the absorbance at $420 \mathrm{~nm}$ is neither due to the NifLbound FAD nor based on a contaminating protein but might originate from a different protein moiety or a covalent post-translational modification upon ammonium presence.

To rule out that the absorbance at $420 \mathrm{~nm}$ results from an artifact upon the denaturation/renaturation procedure we purified apo-NifL from cells grown under aerobic conditions in minimal medium with glutamine as limiting nitrogen source. The absorbance spectrum of this apo-NifL preparation shown in Fig. 4B lacks the absorbance at $420 \mathrm{~nm}$ as it was the case for the corresponding NifL preparation carrying the cofactor (Fig. 2B). This result clearly shows that the $420 \mathrm{~nm}$ absorbance peak in Fig. 4A is not based on an artifact during isolation and renaturation of apo-NifL.

\section{Discussion}

Our goal is to determine how K. pneumoniae NifL may receive and transmit information about the levels of combined nitrogen in cells to NifA. Our starting hypothesis was that changes in the nitrogen status of the cell might affect the redox potential of the FAD moiety bound to NifL, ultimately determining whether the flavin could be reduced by its physiological electron donor. We therefore investigated whether the NifL protein isolated from $E$. coli grown under nitrogen limitation or in the presence of ammonium had different redox potentials. To minimize unphysiological effects upon overexpression, NifL was synthesized at a level at which its function is regulated normally in vivo in response to combined nitrogen and oxygen.

We determined that the redox potential of NifL, synthesized as a fusion protein (MBP-NifL) in $E$. coli in the presence of ammonium, was $-277 \pm 5 \mathrm{mV}$ at $\mathrm{pH} 8.0$ and $25^{\circ} \mathrm{C}$. Assuming that the $\mathrm{pH}$ dependence of the $\mathrm{FAD}_{\mathrm{ox}} / \mathrm{FAD}_{\text {red }}$ couple has a slope of -30 $\mathrm{mV}$, the redox potential of NifL at $\mathrm{pH} 7$ is approx. $-247 \pm 5 \mathrm{mV}$. MBP-NifL synthesized in E. coli under nitrogen starvation had almost the same redox potential $\left(-274 \pm 6 \mathrm{mV}\right.$ at $\mathrm{pH} 8.0$ and $\left.25^{\circ} \mathrm{C}\right)$. These results indicate that the nitrogen source has no apparent influence on the redox potential of MBP-NifL when synthesized in E. coli. Thus the nitrogen signal is apparently not directly transmitted through NifL by stably altering the redox properties of the flavoprotein.

The two MBP-NifL fractions differed, however, in that an absorbance centered at $420 \mathrm{~nm}$ was found only in MBP-NifL synthesized in the presence of ammonium. Analyses of peroxidase activity showed that a possible heme content of the MBP-NifL fraction is lower than $0.5 \%$ indicating that the absorbance at $420 \mathrm{~nm}$ is apparently not based on the presence of a covalent bound heme cofactor. The finding that apoprotein of NifL purified from cells grown in the presence of ammonium still retained the absorbance at $420 \mathrm{~nm}$ further indicates that the $420 \mathrm{~nm}$ absorbance is also not due to the flavin cofactor. One possible explanation for the absorbance at 420 $\mathrm{nm}$ is a post-translational covalent modification of NifL in response to ammonium: such a modification might yield in an inhibitory form of NifL with unchanged redox potential. At this state of experimental data we cannot completely exclude that the absorbance at $420 \mathrm{~nm}$ might be based on an allosteric interaction with a small effector molecule upon ammonium presence. However, it seems to be unlikely to copurify these effector molecules with NifL when apo-NifL is purified from inclusion bodies by denaturation in the presence of $8 \mathrm{M}$ urea. A covalent modification of NifL, however, should be stable during the denaturation procedure.

It still remains to be explained how the nitrogen signal is transmitted to NifL/NifA. One possible candidate for the nitrogen sensing component is the second PII protein, GlnK, which was shown to be required for the non-inhibitory form of $K$. pneumoniae NifL under nitrogen and oxygen limiting conditions in a heterologous $E$. coli system [11]. If $K$. pneumoniae $\mathrm{GlnK}$ is indeed the sensor or intermediate messenger responsible for carrying the nitrogen signal to 
the nitrogen fixation regulatory system, it remains to be found how GlnK interacts with the NifL/NifA system.

The redox potential determined for $K$. pneumoniae NifL produced under nitrogen limitation or abundance is significantly lower than that which was determined for $A$. vinelandii NifL $(-226 \mathrm{mV}$ at $\mathrm{pH} 8.0$ [7]). In $K$. pneumoniae as in $A$. vinelandii, the redox state of the flavoprotein is thought to influence its ability to modulate the NifA activity in response to the oxygen levels. The physiological electron donors for NifL in A. vinelandii and $K$. pneumoniae have not yet been identified. Because nif induction in $K$. pneumoniae under nitrogen and oxygen limiting conditions requires iron, we postulated that the oxygen signal is passed to NifL via an iron-containing protein [13]. One possible candidate for this role is a flavoheme protein from E. coli studied by Poole and his colleagues, which is believed to function as an oxygen sensor in E. coli [20]. In vitro, this flavoheme protein can reduce NifL of $A$. vinelandii with $\mathrm{NADH}$, as it is the case for the spinach ferredoxin: NADP oxidoreductase in the absence of an electron mediator [7]. However, NifL reduction by these electron donors in vitro is very slow, indicating that they might not be the physiological electron donors. In addition to the differences in their redox potentials, the NifL of $K$. pneumoniae and $A$. vinelandii differ significantly in that the apoprotein of NifL K. pneumoniae completely lacking its cofactor can inhibit NifA activity in vitro, indicating that FAD is not essential for the inhibition process [5]. However, Hill et al. [6] showed for A. vinelandii that the refolded apoprotein of NifL - lacking the flavin moiety - failed to inactivate NifA under oxidizing conditions. These differences between the NifL proteins might indicate that the mechanisms for sensing and or transmission of the environmental signals to NifA differ in some regards in the two species.

\section{Acknowledgements}

We thank Gerhard Gottschalk for generous support and helpful discussions; Tim Ikeda and Andrea Shauger for critical reading the manuscript. This work was supported by the Deutsche Forschungsgemeinschaft and the Fonds der Chemischen Industrie.

\section{References}

[1] M. Filser, M. Merrick, F. Cannon, Cloning and characterization of nifLA regulatory mutations from Klebsiella pneumoniae, Mol. Gen. Genet. 191 (1983) 485-491.

[2] R. Dixon, The oxygen-responsive NifL-NifA complex: a novel two-component regulatory system controlling nitrogenase synthesis in gamma-proteobacteria, Arch. Microbiol. 169 (1998) 371-380.

[3] F. Narberhaus, H.-S. Lee, R.A. Schmitz, L. He, S. Kustu, The C-terminal domain of NifL is sufficient to inhibit NifA activity, J. Bacteriol. 177 (1995) 5078-5087.

[4] C. Sidoti, G. Harwood, R. Ackerman, J. Coppard, M. Merrick, Characterization of mutations in the Klebsiella pneumoniae nitrogen fixation regulatory gene nif $L$ which impair oxygen regulation, Arch. Microbiol. 159 (1993) 276-281.

[5] R.A. Schmitz, NifL of Klebsiella pneumoniae carries an Nterminally bound FAD cofactor, which is not directly required for the inhibitory function of NifL, FEMS Microbiol. Lett. 157 (1997) 313-318.

[6] S. Hill, S. Austin, T. Eydmann, T. Jones, R. Dixon, Azotobacter vinelandii NifL is a flavoprotein that modulates transcriptional activation of nitrogen-fixation genes via a redoxsensitive switch, Proc. Natl. Acad. Sci. USA 93 (1996) 21432148.

[7] P. Macheroux, S. Hill, S. Austin, T. Eydmann, T. Jones, S.O. Kim, R. Poole, R. Dixon, Electron donation to the flavoprotein NifL, a redox-sensing transcriptional regulator, Biochem. J. 332 (1998) 413-419.

[8] L. He, E. Soupene, S. Kustu, A new role of NtrC: control of Klebsiella pneumoniae NifL activity, J. Bacteriol. 179 (1997) 7446-7455.

[9] E. Söderbäck, F. Reyes-Ramirez, T. Eydmann, S. Austin, S. Hill, R. Dixon, The redox- and fixed nitrogen-responsive regulatory protein NifL from Azotobacter vinelandii comprises discrete flavin and nucleotide-binding domains, Mol. Microbiol. 28 (1998) 179-192.

[10] A. Holtel, M.J. Merrick, The Klebsiella pneumoniae PII protein $(g \ln B$ gene product) is not absolutely required for nitrogen regulation and is not involved in NifL-mediated nif gene regulation, Mol. Gen. Genet. 217 (1989) 474-480.

[11] L. He, E. Soupene, A. Ninfa, S. Kustu, Physiological role for the GlnK protein of enteric bacteria: relief of NifL inhibition under nitrogen-limiting conditions, J. Bacteriol. 180 (1998) 6661-6667.

[12] H.S. Lee, F. Narberhaus, S. Kustu, In vitro activity of NifL, a signal transduction protein for biological nitrogen fixation, J. Bacteriol. 175 (1993) 7683-7688.

[13] R.A. Schmitz, L. He, S. Kustu, Iron is required to relieve inhibitory effects of NifL on transcriptional activation by NifA in Klebsiella pneumoniae, J. Bacteriol. 178 (1996) 4679-4687.

[14] V. Massey, in: B. Curti, G. Zanetti, S. Ronchi (Eds.), A Simple Method for the Determination of Redox Potentials in Flavins and Flavoproteins, Walter de Gruyter and Co., Berlin, 1991 pp. 59-66. 
[15] K. Minneart, Measurement of the equilibrium constant of the reaction between cytochrome $c$ and cytochrome $a$, Biochim. Biophys. Acta 110 (1965) 42-56.

[16] W.W. Fish, Rapid colorimetric micromethod for the quantitation of complexed iron in biological samples, Methods Enzymol. 158 (1988) 357-364.

[17] M.M. Bradford, A rapid and sensitive method for the quantitation of microgram quantities of protein utilizing the principle of protein-dye binding, Anal. Biochem. 72 (1976) 248254.
[18] U.K. Laemmli, Cleavage of structural proteins during the assembly of the head of the bacteriophage T4, Nature 227 (1970) 680-685.

[19] P.E. Thomas, D. Ryan, W. Levin, An improved staining procedure for the detection of the peroxidase activity of cytochrome P-450 on sodium dodecyl sulfate polyacrylamide gels, Biochemistry 75 (1976) 168-176.

[20] R.K. Pool, Oxygen reactions with bacterial oxidases and globins: binding, reduction and regulation, Antonie van Leeuwenhoek 65 (1994) 289-310. 